\title{
Interfaces entre austeridade, necropolitica e o mito da pandemia democrática: provocaçôes à brasileira
}

I ${ }^{1}$ Jacks Soratto, ${ }^{2}$ Diego Floriano de Souza I

\author{
1 Programa de Pós-Graduação em Saúde Coletiva, Universidade do Extremo Sul Catarinense. Criciúma-SC, Brasil (jackssoratto@hotmail.com). \\ ORCID: 0000-0002-1339-7268 \\ 2 Programa de Residência Multiprofissional em Atenção Básica Saúde da Família, Saúde Coletiva e Saúde Mental, Universidade do Extremo \\ Sul Catarinense. Criciúma-SC, Brasil (diegoflorianodesouza@hotmail.com). ORCID: 0000-0002-2597-7104 \\ Recebido em: 08/05/2021 \\ Aprovado em: 03/06/2021 \\ Revisado em: 08/07/2021
}

DOI: http://dx.doi.org/10.1590/S0103-73312021310310

O Brasil passou pela redemocratizaçáo no final da década de 1980, quando movimentos sociais, comunidade cientifica e a participação popular se uniram, exigindo saúde como um direito, de modo que essa reinvindicaçáo foi impetrada na Constituição Federal de 1988 (BRASIL, 1988). Para a efetivaçáo desse direito, propôs-se a criação de um sistema de saúde que assumisse como principal compromisso à vida, e que tivesse como premissas: universalidade, integralidade e equidade (BRASIL, 1990).

O Sistema Único de Saúde (SUS) deve garantir acesso aos serviços de saúde, em todos os ciclos da vida, de todos os cidadáos brasileiros. No entanto, parece que houve certo distanciamento entre a condução das políticas públicas em saúde e os interesses coletivos de onde a vida acontece.

A participação da população nas instâncias decisórias, que é um dos pilares do SUS, foi sendo gradativamente minada, perdendo sua potência de "instituinte", operando agora no delicado status do "instituído" e, por consequência, fragilizando aquilo que em outro momento foi a expressão máxima de sua conquista (FLEURY, 2009). Isso possibilitou que partes da saúde suplementar e indústria farmacêutica 
exercessem pressões políticas onde o sistema historicamente apresenta maior fragilidade, a saber, seu financiamento.

Com o capital financeiro ditando grande parte dos rumos da saúde pública no país, deu-se, a partir de 2016, início à agenda de austeridade, que começou por cortes identificados como limitaçôes orçamentárias na educação e na saúde, e que teve como ápice a aprovação da Emenda Constitucional número 95 (EC-95), que estabelece um limite de investimento por um período de até 20 anos.

A austeridade fiscal caracteriza-se principalmente por aumento da carga tributária e medidas que restringem a oferta de benefícios, bens e serviços públicos, em razão de cortes de despesas e/ou da realização de reformas estruturais (SANTOS; VIEIRA, 2018). Como proposto pela EC-95, e seu teto de gastos na saúde, onde em um exercício prospectivo, estimou-se que as perdas em investimentos no SUS poderiam variar de $\mathrm{R} \$ 168$ bilhōes a $\mathrm{R}$ \$ 738 bilhōes entre 2017 a 2036, a depender do crescimento do PIB nos próximos anos. No caso da assistência social, a perda de recursos poderia chegar a $\mathrm{R} \$ 868$ bilhóes em vinte anos (SANTOS et al., 2018).

Essa "perda" ou ausência de investimento no SUS implicará diretamente menor financiamento para à saúde, e consequentemente, uma redução de investimento em proteçẫo social, refletindo a população na forma de redução na oferta de serviços de saúde, fechamento ou custeio de unidades de atenção primária, média e alta complexidade, redução no número de equipes, sucateamento de equipamentos e serviços, redução das ações de vigilância em saúde, entre outros prejuízos, dificultando acesso às ações de prevenção, promoção e atenção à saúde, resultando em menos cuidado à vida, onde o impacto distributivo imposto pela EC-95 em relação ao gasto social, em particular o gasto com saúde e educação, tende a aprofundar as desigualdades sociais no Brasil (DWECK et al., 2018).

Em meio a este cenário de austeridade surgiu, em dezembro de 2019, na cidade de Wuhan, a China, o que viria se tornar uma nova pandemia, causada por um novo tipo de coronavírus identificado como SARS-CoV-2 e popularmente chamado de Covid-19 (OPAS, 2020). A disseminação ocorreu exponencialmente na China, Itália, Espanha, França, Rússia, Reino Unido e Estados Unidos, entre outros tantos países ambos despreparados para lidar com uma pandemia, mesmo aqueles com sistemas universais mais sólidos, como o Brasil.

Políticas de austeridade aliadas à pandemia foram o casamento perfeito para o fortalecimento dos princípios necropolíticos se efetivem a partir do negligenciamento 
de algumas doenças, inclusive a intensificação de situações de violência doméstica, feminicídio, encarceramento, trabalho análogo à escravidão, desemprego, fome etc., mas principalmente pela apropriação da morte pelo Estado, e pela capacidade de o mesmo decidir quem morre, quando morre, de que forma morre (MBEMBE, 2017).

$\mathrm{Na}$ necropolítica, sua expressão máxima consiste "[...] no poder e na capacidade de ditar quem pode viver e quem deve morrer" (MBEMBE, 2017, p. 5), utilizando artifícios e atores do Estado, operando à margem da lei, por onde se cria a ideia de que a "paz" tende a assumir o rosto de uma "guerra sem fim", conduzida e legitimada pelo Estado no qual "[...] o direito soberano de matar não está sujeito a qualquer regra. Onde o soberano pode matar a qualquer um ou de qualquer maneira" (MBEMBE, 2018, p. 36).

Em meio esse cenário pandêmico, vai se estruturando a política da morte, afetando sobretudo a população carcerária, $\mathrm{LGBTQ}^{+}$, negros, indígenas, quilombolas, moradores em situação de rua ou de comunidades periféricas, pessoas com deficiência, portadores de doenças crônicas, migrantes, refugiados e os mais idosos. Por sua vez, os que têm histórico de atleta não precisam se preocupar, como sustenta o presidente brasileiro Jair Messias Bolsonaro: "No meu caso particular, pelo meu histórico de atleta, caso fosse contaminado pelo vírus, não precisaria me preocupar, nada sentiria, ou seria, quanto muito acometido por uma gripezinha" (BOLSONARO, 2020, 3:17 a 3:31 minutos).

Mesmo com diversas medidas de auxílio aos municípios e estados, o governo brasileiro parece fortalecer esse projeto necropolítico, em especial pelas posturas pessoais de seu representante maior, somadas à demora de uma reposta eficaz do Ministério da Saúde no protagonismo e coordenação do enfrentamento da pandemia.

O suposto projeto necropolítico, ainda que sem uma explicitação da sua autoria, é fortalecido com um discurso negacionista do agravo sob o pretexto de uma doença para todos. Não obstante, a tese da pandemia democrática começa a ser descontruída quando considerarmos as distintas realidades de moradia no Brasil, onde em muitas comunidades o número de habitantes geralmente é alto, o que dificulta também medidas de isolamento domiciliar (OLIVEIRA et al., 2020). E ainda, para muitos há necessidade de trabalho para garantir o sustento próprio de seus familiares, sendo os sujeitos obrigados a encarar as ruas e o transporte público superlotado, que não atende às medidas de distanciamento necessárias para evitar a transmissão do vírus (CAPONI, 2020). 
Por outro lado, embora já passado mais de um ano do início dos casos no país, o Ministério da Saúde ainda não apresentou uma proposta de contingência clara; carece de efetividade de plano estratégico para o combate da pandemia junto a povos mais vulneráveis atingidos pelo Covid-19; contabilizou trocas de ministros da Saúde em tempo reduzido, quando, em um dos momentos mais cruciais da pandemia, havia um ministro sem identificação profissional com o Ministério.

Nesse cenário, ainda cabe nos questionar se todos dispóem das mesmas condiçóes de prevenção ou, ainda, se podemos afirmar que se trata de uma pandemia democrática? Acreditamos que não, porque nem todos estão expostos na mesma medida e nem possuem, ao seu alcance, condiçôes para sua proteção; e do outro, proteção inclusive alimentar. A maioria das açôes desenvolvidas pelo governo ainda não alcançaram de maneira efetiva a totalidade do território onde a vida acontece, de modo que se necessita urgentemente que esses aspectos sejam considerados para um melhor enfretamento da pandemia.

Destarte, a população, que já vinha sofrendo com os reflexos da austeridade, poderá, acredita-se, ficar ainda mais desamparada, desassistida e conduzida a um caminho nefasto, ainda que não anunciado explicitamente, onde a morte deixa de ser um acontecimento natural e passa a ser instrumento de um Estado pautado em uma possível lógica do necropoder. ${ }^{1}$

\section{Referências}

AQUINO, E. M. L. et al. Medidas de distanciamento social no controle da pandemia de Covid-19: potenciais impactos e desafios no Brasil. Ciênc. Saúde coletiva. Rio de Janeiro, v. 25, supl. 1, p. 2423-2446, jun. 2020. Disponível em: <http://www.scielo.br/scielo.php?script=sci_ arttext\&pid $=S 1413-81232020006702423 \& \operatorname{lng}=e n \& n r m=i s o>$. Acesso em: 27 jul. 2020. https://doi.org/10.1590/1413-81232020256.1.10502020.

BOlSONARO, J. M. Pronunciamento do presidente da República, Jair Bolsonaro (24/03/2020). Planalto [on line]. Brasília, DF. Disponível em: https://www.youtube.com/watch?v=Vl_DYbXaAE. Acesso em: 29 mar. 2021.

BRASIL. Ministério da Saúde. Lei 8.080, de 19 de setembro de 1990. Dispóe sobre as condiçóes para a promoção, proteção e recuperação da saúde, a organização e o funcionamento dos serviços correspondentes e dá outras providências. Diário Oficial da Uniāo, Brasília, DF, 19 set. 1990a. Seção 1. Disponível m:http://portal.saude.gov.br/portal/arquivos/pdf/Lei8142.pdf . Acesso em: 14 jul. 2020. 
. Senado Federal. Constituição da República Federativa do Brasil. Brasília, DF: Senado Federal, 1988.

CAPONI, S. Covid-19 no Brasil: entre o negacionismo e a razão neoliberal. Estud. av., São Paulo, v. 34, n. 99, p. 209-224, ago. 2020. Disponível em: <http://www.scielo.br/scielo. php?script=sci_arttext\&pid=S0103-40142020000200209\&lng=en\&nrm=iso $>$. Acesso em: 23 nov. 2020. https://doi.org/10.1590/s0103-4014.2020.3499.013 .

DWECK, E. et al. Impacto da austeridade sobre o crescimento e a desigualdade no Brasil. In: ENCONTRO NACIONAL DE ECONOMIA POLÍTICA, 23, 2018, Niterói. Anais... Disponível em: http://www.sep.org.br/anais/Trabalhos\%20para\%20o\%20site/Area\%203/53. pdf. Acesso em: 21 nov. 2020.

FLEURY, S. Reforma sanitária brasileira: dilemas entre o instituinte e o instituído. Ciênc Saúd Colet. Rio de Janeiro, v. 14, n. 3, p. 743-752, 2018. Disponível em: <https://www.scielosp.org/ article/csc/2009.v14n3/743-752/pt/\#ModalArticles> Acesso em: 21 nov. 2020.

FOUCAULT, M. Vigiar e punir. Petrópolis, RJ: Vozes, 2014.

GRISOTTI, M. Pandemia de Covid-19: agenda de pesquisas em contextos de incertezas e contribuiçôes das ciências sociais. Physis, Rio de Janeiro, v. 30, n. 2, e300202, 2020. Disponível em: http://www.scielo.br/scielo.php?script=sci_arttext\&pid=S0103$73312020000200301 \& \operatorname{lng}=$ en\&nrm=iso . Acesso em: 27 jul. 2020. https://doi.org/10.1590/ s0103-73312020300202.

HARZHEIM, E. et al. Açóes federais para apoio e fortalecimento local no combate ao COVID-19: a Atenção Primária à Saúde (APS) no assento do condutor. Ciênc. Saúde coletiva. Rio de Janeiro, v. 25, supl. 1, p. 2493-2497, jun. 2020. Disponível em: <http://www.scielo. br/scielo.php?script=sci_arttext\&pid=S1413-81232020006702493\&lng=en\&nrm=iso $>$. Acesso em: 27 jul. 2020. http://dx.doi.org/10.1590/1413-81232020256.1.11492020

LIMA, D. L. F. et al. Covid-19 no estado do Ceará, Brasil: comportamentos e crenças na chegada da pandemia. Ciênc. Saúde coletiva. Rio de Janeiro, v. 25, n. 5, p. 1575-1586, 2020. Disponível em: <http://www.scielo.br/scielo.php?script=sci_arttext\&pid=S141381232020000501575\&lng=en\&nrm=iso>. Acesso em: 27 jul. 2020. https://doi. org/10.1590/1413-81232020255.07192020.

LIMA, F. Bio-necropolítica: diálogos entre Michel Foucault e Achille Mbembe. Arq. bras. psicol., Rio de Janeiro , v. 70, n. spe, p. 20-33, 2018. Disponível em: <http://pepsic.bvsalud. org/scielo.php?script=sci_arttext \&pid=S1809-52672018000400003\&lng=pt\&nrm=iso $>$. Acesso em: 27 jul. 2020.

MBEMBE, A. Necropolítica. São Paulo: n-1 ediçôes; 2018.

. Politicas da inimizade. Lisboa: Antígona, 2017. 
MERHY, E. E. $O$ ato de cuidar: a alma dos serviços de saúde. Texto produzido a partir do texto didático: o ato de cuidar como um dos nós críticos-chave dos serviços de saúde. Curso DMPS/FCM/Unicamp, 1999. Disponível em: <https:/www.pucsp.br/prosaude/downloads/ territorio/o-ato-de-cuidar.pdf>

MERHY, E. E.; BERTUSSI, D. C.; SANTOS, M. L. de M. dos S. Não basta acesso universal; é preciso um sistema universal de saúde. Disponível em: <https://www.viomundo.com.br/ blogdasaude/merhy-bertussi-e-santos-nao-basta-acesso-universal-e-preciso-um-sistemauniversal-de-saude.html>. Acesso em: 5 jun. 2020.

OLIVEIRA, R. G. de et al. Desigualdades raciais e a morte como horizonte: consideraçóes sobre a COVID-19 e o racismo estrutural. Cadernos de Saúde Pública, v. 36, n. 9, e00150120. Disponível em: <https://doi.org/10.1590/0102-311X00150120>. Acesso em: 23 nov. 2020. https://doi.org/10.1590/0102-311X00150120 .

ORGANIZAÇÃO PAN-AMERICANA DA SAÚDE. OMS afirma que COVID-19 é agora caracterizada como pandemia. Disponível em: <https://www.paho.org/bra/index. php?option=com_content $\&$ view=article $\&$ id $=6120$ :oms-afirma-que-covid-19-e-agoracaracterizada-como-pandemia\&Itemid=812>. Acesso em: 27 mar. 2020.

SANTOS, I. S.; VIEIRA, F. S. Direito à saúde e austeridade fiscal: o caso brasileiro em perspectiva internacional. Ciênc. saúde coletiva, Rio de Janeiro, v. 23, n. 7, p. 2303-2314, jul. 2018. Disponível em: <http://www.scielo.br/scielo.php?script=sci_arttext\&pid=S1413-81232018000702303\&ln g=pt\&nrm=iso $>$. Acesso em 27 jul. 2020. https://doi.org/10.1590/1413-81232018237.09192018. SCHARAMM, J. M. de A.; PAES-SOUSA, R.; MENDES, L. V. P. Políticas de austeridade e seus impactos na saúde. Centro de Estudos Estratégicos. Rio de Janeiro, v. 1, n. 1, p. 1131, 2018. Disponível em: <http://www.cee.fiocruz.br/sites/default/files/1_Joyce $\% 20$ M-R\%C3\%B4mulo\%20P-Luiz\%20V_austeridade_1.pdf>.

\section{Nota}

${ }^{1}$ J. Soratto: concepção, planejamento, análise, interpretaçáo e redação do texto. D. F. de Souza: concepção, planejamento, redação e revisão do texto. 